\title{
Lost in translation: \\ A study of (mis)conceptions, (mis)communication and concerns when implementing gamification in corporate (re)training
}

\author{
Adam Palmquist \\ Applied IT, University of \\ Gothenburg, Sweden \\ adam.palmquist@ait.gu.se
}

\begin{abstract}
This exploratory study concerns companies in the manufacturing industry that consider implementing gamification in their online training to satisfy the accelerating demand for workforce upskilling. Through participation in different gamification design workshops with a gamification studio and its clients, this study aims to identify what topics are discussed and should be considered when designing a gamified solution for training in the manufacturing industry. The study raises the propositions that gamification needs 1) a more robust definition in business to business exchange; 2) a better explanation of how performance outweighs effort; 3) consideration of the senior users and/or the social norms that exist in the manufacturing industry.
\end{abstract}

\section{Introduction}

Given the contemporary manufacturing-todigitization transformation in the manufacturing industry, a need for rapid retraining of the existing workforce has been highlighted. Up to $14 \%$ of the global workforce will during the upcoming decade need retraining as digitalization and automation transform work [1]. Retraining is also an issue concerning the increase in retirement age in European countries [2]. With a workforce operational in a rapidly changing work environment, the necessity for retraining, upskilling, and continuous learning are essential components for professional success throughout the digital shift [3]. Gamification (i.e., game mechanics in non-game contexts) is one method that has been proposed to achieve efficient learning situations [4]. Research has suggested that learning and employee training could benefit from gamification [5][6]. However, other studies indicate that gamification is challenging to design and develop effectively [7]-[9]. The current study attempts to contribute to the discussion on implementing gamification in corporate training. By attending six gamification design workshops (GDWs) examining gamification for corporate training in the manufacturing industry, this study demonstrates the - often not straightforward interactions between a gamification studio and its clients. The investigation seeks the applicability of gamification in corporate workforce retraining and the associated barriers, challenges, and obstacles. The study aims to answer the following research question (RQ):

Which discussion themes are recurring when gamification professionals and business specialists prepare to implement gamification in digital corporate (re-)training courses?

To answer the RQ, the author followed a gamification studio for nine months, participating in six different GDWs with companies seeking to add gamification to their corporate online (re)training programs (COTPs).

\subsection{Gamification in corporate training}

To date, the discussion about gamification for learning has primarily been concerned with education, rather than retraining in professional environments [5]. It is important not to view the areas of application of gamification as synonymous: for example, in the educational domain, success is generally related to the individual student's learning, but, in training, success is also measured by the employee's behavioral change that brings investment returns for the organization [10]. The end-user's age has been highlighted as a problematic factor in comparisons between education and training (when discussing gamification) [5][11]. Regarding learning outcomes and attitudes toward game-based training, a recent study showed that groups receiving gamified training were significantly more satisfied with the training compared with the control group [12]. However, the overall test scores did not differ between the two groups. Trainees in the control group scored marginally higher for procedural knowledge than trainees in the gamified course. Moreover, the study showed that the participants' attitudes toward gamebased learning did not appear to positively or negatively 
affect the learning outcome [12]. Another study investigated employees' intentions to engage in gamified online training, examining the relationships between the variables performance expectancy, effort expectancy, facilitating conditions, and familiarity with gamification in learning [13]. The research was conducted through an application with 136 participants and used Structural Equation Modeling data analysis [13]. The key finding was that the performance expectancy (a belief that using a device will benefit gains) was the most influential variable for an employee's intention to invest in the course's gamification. In the deduction of the result, the Unified Theory of Acceptance and Use of Technology (UTAUT) model was applied to explain the relationships [14].

Research on gamified corporate training concentrates on the relationships between gamification and outcomes, the later phases in gamification implementation. The present study has a theoryadvancing approach stressing the importance of identifying and documenting a theoretical and practical problem to guide both researchers and practitioners further in their line of work. Although gamification has become more prevalent in contemporary technologies, designing gamification in real-life situations has its challenges. Both practitioners and researchers acknowledge that gamification is challenging to implement. These challenges arise from the differences among participants' backgrounds, goals, and understanding of gamification [15][16]. In addition to highlighting the lack of robust field case studies describing how to design gamification for training, studies suggest that gamification design needs multidisciplinary research methods with a variety of approaches to grasp the gamification business's overall comprehension [5][6][15]. Researchers argue that there is insufficient detailed guidance or information about design gamification and that contemporary approaches to creating gamified solutions lack comprehensive descriptions of the targeted end-users [7][8].

Overall, research on gamification design for corporate training consistently indicates a lack of structured approaches to and understanding of endusers, use contexts, and actual development praxis. The gamification business has snowballed over last decade and has been simultaneously surrounded by an aura of excitement and hype, which has made it challenging to frame for both researchers and professionals [17]. Gamification was included in the Gartner Hype Cycles for Emerging Technologies [18], which probably contributed to the excitement when the advisory firm announced that more than $50 \%$ of organizations that work with innovation processes would gamify their processes by 2015 [19]. Furthermore, in business and economics literature, gamification is sometimes described as a "truly revolutionizing concept that might change the way employees perceive work and [...] might transform corporations and business in general" [20 p XI]. Statements like these made gamification a highly touted behavior design trend in the 2010s [21]. The excitement has rendered the interpretation of the gamification context difficult [9]. Although the gamification studies of recent years have a higher academic standard, Nacke and Deterding believe that much still needs to be done for the research field to mature [22].

\subsection{The case}

In late 2018, a gamification studio was invited to a private seminar held at a technology university in Sweden. The seminar concerned game-based learning and training strategies in the fourth industrial revolution, Industry 4.0. Approximately 40 individuals from different international manufacturing corporations attended. The studio delivered a 20 -minute presentation on gamification in learning and displayed its gamification platform, GWEN, previously implemented in the university's learning management system (LMS) as part of a research project conducted at the university. After the presentation, the gamification studio was approached by several of the manufacturing companies interested in using gamification in their latest COTPs. The following year, the gamification studio conducted six GDWs as part of various feasibility investigations for gamification in different COTPs. The present study was primarily designed to evaluate the gamification studio's design workshop method. The author of the current study was invited to participate, observe, collect data, analyze, and write a report to the gamification studio to help them to improve their GDWs. However, during the first GDW attended, it became apparent that the workshop's discussions suggested anything but a straightforward acceptance of gamification. Therefore, the author decided to observe the discussions more closely during the subsequent GDWs. After the two initial GDWs with two different manufacturing companies, the author decided to design a study to condense the discussion about gamification in training between a gamification studio and different manufacturing companies.

\subsection{The sight and its informants}

The gamification studio that participated in this study and staged the GDWs, operates in the field of education, retraining, and human resources. They have 
performed over 40 gamification implementations using their platform. The studio define gamification as "using elements from the world of games in a non-gaming environment"[23]. When starting a gamification project, the studio conducts a feasibly study. In the feasibility study, an obligatory GDW is held with the clients to determine the goals, rules, and design of the gamification implementation. The companies (Table 1) were represented by a diverse group of professionals, comprised of individuals from the companies' human resource management, operations management, research and development, and training and development functions. The common denominator for the group was that they possessed extensive knowledge of company's processes, long-term goals, why employee training is required, how corporate training is executed, and the end-users. This group is hereafter called the "specialists." Gamification designers (GDs) in this context were responsible for the gamification scheme of the discussed courses. The GDs organized and pushed the GDWs forward by asking different questions of the specialists.

The gamification studio used a three-step GDW, consisting of a course analysis, a user analysis, and a gamification behavior and goal analysis. Each GDW took approximately three to five hours to complete, and the format was similar to that of a round table discussion. The GDW started with a brief presentation and the studio's definition of gamification: "gamification uses elements from games in a nongaming environment." The specialists then began to describe their target groups. The questions concerned the target group members' age, gender, length of employment by the company, frequency of corporate training, educational background, and personality. Furthermore, the specialists' perceived notion of the target group's attitudes and opinions toward subjects such as games and learning, e-learning, and the group's digital experience was investigated. Moreover, the studio's designers asked questions about the current obstacles around the enterprise's existing training programs, emphasizing the existing target groups. The designers also asked questions about why the specialists desired to implement a gamified course for their target group and what performance indicators should be evaluated for the success of the implementation of the e-learning course.

The information gathered was logged into different categories during the workshop and was included in the gamification design document (GDD) (Figure 1). The GDD was the outcome of the GDWs and enabled the designers and developers to begin to understand the intended audience and circumstances for the gamification implementation. The document contained audience characteristics (e.g., existing knowledge, gamification experience level, drives, and best practices) and circumstance characteristics (e.g., platform, activity, and key performance indicators before and after a gamification implementation). When finalized, the document was presented to the client as a 20-page gamification feasibility report, on which the

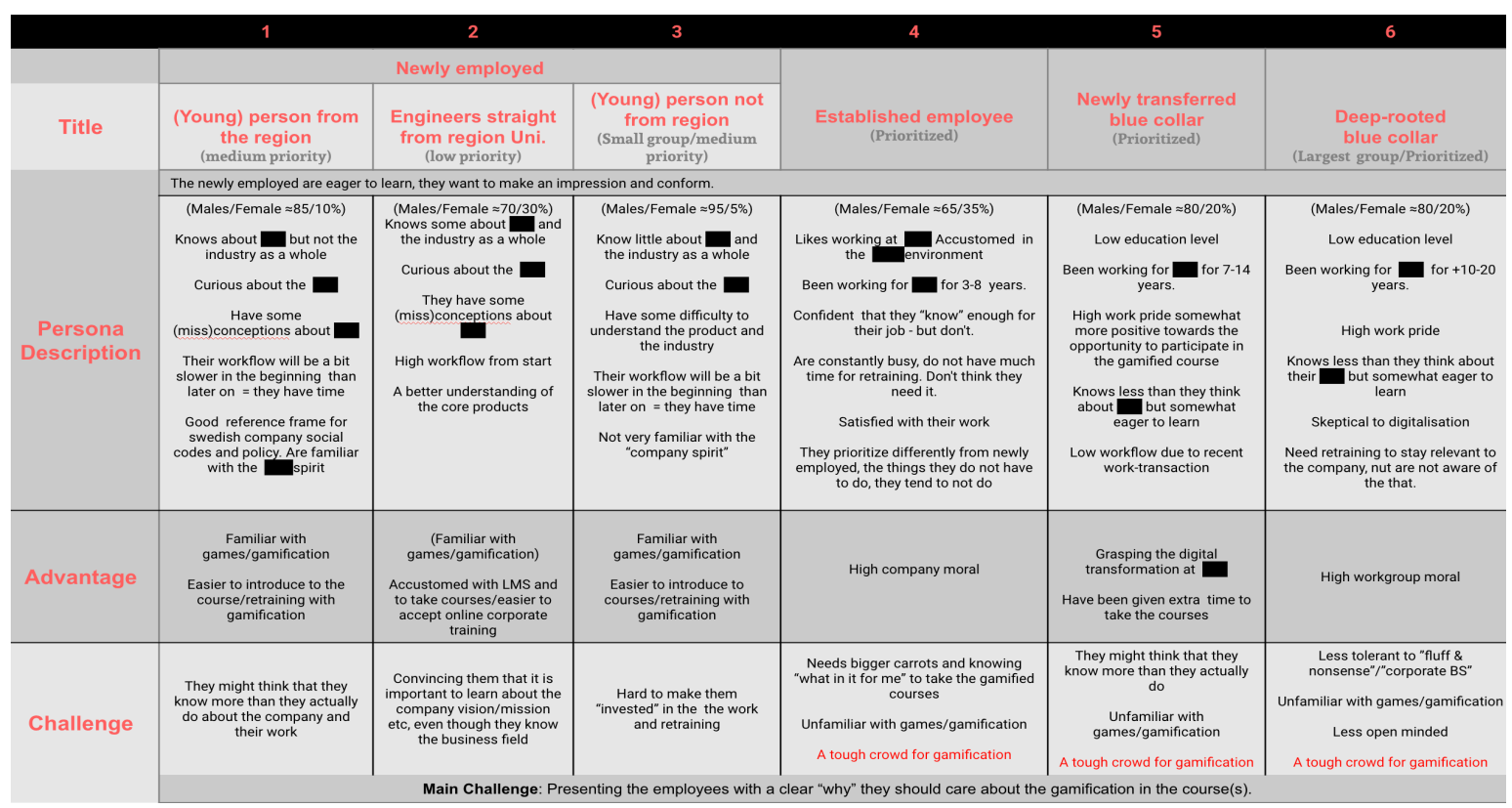

Figure 1: The persona slide (slide 7 of 19) in one of the gamification design documents analyzed 
client then based their decision as to whether to start to implement gamification in their existing training.

\section{Method}

In the present study, the data gathered related to the GDWs, which were part of several gamification feasibility studies for gamification in the COTPs. This case study's timeframe was nine months and used two different methods in its research design: participant observation and document analysis in the investigations of the sources (Figure 2).

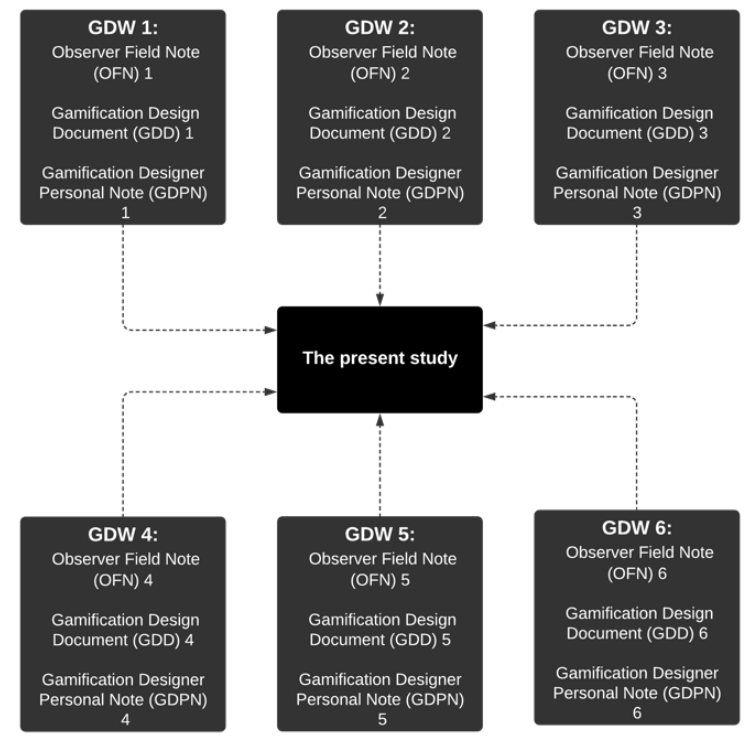

Figure 2 Data source flowchart

A qualitative method of document analysis was used for interpreting the GDDs in the study [24]. Documents were used and analyzed in an organized way. In this case, they involved the relationships between design, development, and product. The strength of a document analysis method often contributes to the exactness of the data, and written text aimed for others requires clear communication.
However, this was a shortcoming of the current study's method and data; documents were produced for a purpose other than research or the researcher's agenda. [24]. Being aware that the design documents would not provide enough detail to give a trustworthy answer to the RQ, the author added a second qualitative method and dataset to the research design: participant observation. The participant observation method gives the researcher a nuanced understanding of human behaviors when they act in a situation or interact with an environment [25]-[27]. The author attempted to practice the informant's role and be a part of the group dynamic [25] by participating in the six different GDWs. Before every GDW, the practitioners were informed and gave consent. The author took part in the GDWs as naturally as possible and, at the same time, took records (observer field notes; OFNs), based on what occurred during the workshops. The OFNs were collected throughout all the GDWs. The field notes covered the participants', designers', and specialists' ongoing discussions and the main events happening during the GDWs.

One weakness in the study's method was that the author did not make a video or audio recording of the observations, which is customary [25]-[27]. There were two main reasons for this. First, both the gamification studio's workshop leader and most of the manufacturing companies were hesitant to record the workshop, on the basis that that it could have a restraining effect on workshop participants and inhibit them from discussing gamification freely in the workshops. Secondly, several of the corporations said that, if there was going to be a video or audio recording on the corporation's premises, they had to involve their security department, which would have extended the lead time as the gamification studio and all its personnel would have had to be inspected to ensure avoidance of industrial espionage. This lead time was not an option for the gamification studio nor the corporations. For those reasons, the author was able to take only field notes.

\begin{tabular}{|c|c|c|c|c|c|}
\hline \multicolumn{7}{|c|}{ Table 1. The companies in the gamification design workshops } \\
\hline $\begin{array}{c}\text { GDW } \\
\text { Number }\end{array}$ & Industry & Participants & $\begin{array}{c}\text { Participants' } \\
\text { age range }\end{array}$ & $\begin{array}{c}\text { Training } \\
\text { Design } \\
\text { workshop } \\
\text { period }\end{array}$ \\
\hline 1 & $\begin{array}{c}\text { Automotive company } \\
\text { Training consultants } \\
\text { in Industry 4.0 }\end{array}$ & 6 & $45-60$ & $\begin{array}{c}\text { New materials related } \\
\text { to Industry } 4.0\end{array}$ & December 2018 \\
\hline 2 & $\begin{array}{c}\text { Research Institute } \\
\text { focusing on Industry } \\
4.0\end{array}$ & 8 & $40-50$ & 3D printing & December 2018 \\
\hline 3 & Robot manufacturing & 5 & $40-60$ & Internet of things (IoT) & February 2019 \\
\hline 4 & $\begin{array}{c}\text { Manufacturing } \\
\text { company }\end{array}$ & 5 & $45-60$ & Onboarding for the \\
smart factory & February 2019 \\
\hline 5 & Maritime company & 6 & $40-55$ & 21-century work skills & August 2019 \\
\hline 6
\end{tabular}


After each GDW, the OFNs were immediately processed and underwent an initial coding process [28]. The record focused on the participants' expressed thoughts and feelings, attitudes, emotions, reflections, sentiments, opinions and moods and on their approach to attending the GDWs. These indications could be criticized, as they are difficult to measure objectively [26]. However, this study's aim was exploratory rather than explanatory, achieving relevance while sacrificing some precision, and generalizability was necessary. The GDD had to be finalized by the GD, which took approximately three weeks, before the author could initiate analyses of the data. The GDD, like the OFNs, underwent an initial coding process focusing on excerpts, quotations, and passages that could contribute to comprehending the case. Although personal notes were collected from the gamification team, which gave some information, the change of GDs during the six GDWs resulted in the variable quality of these personal notes, and therefore they had limited value for this study. The personal notes functioned mainly as a spiritlevel for the author in validating and balancing the other two major datasets. The notes proved valuable when the different themes in the study were defined. The initial coding of the data collected throughout the study period provided an abductive approach to the material. The author steadily moved back and forth between new and pre-existing data, searching for patterns to develop the best possible understanding of the case at hand. When all the data had been collected, each of the datasets underwent a secondary focused coding [28].

All collected data were analyzed with help of the MAXQDA software to detect communication patterns between the datasets collected through the two qualitative methods. The author utilized the MAXQDA software coding system, connecting and clustering the patterns. The MAXQDA coding system was used to construct an affinity diagram according to the patterns detected in the material [25]. The data was processed and read by the author several times, and thus communication patterns emerged. The author searched the emerging patterns for corresponding meaning units [28], words, and sentences that expressed similar meanings, enabling the derivation of thematic clusters. The preceding initial coding and the thematic coding were performed separately for the two datasets, facilitating the creation of similar themes connecting the collected data. The evaluation of how these patterns were linked led to the identification of corresponding themes in both datasets. The collected data material was rich and extensive; therefore, some themes had to be omitted from this report for conciseness due to this conference's page limitation. However, these findings will be presented in a forthcoming journal article. In the meantime, in the current study, the three most frequent patterns were chosen to form the different themes for discussion.

For validity and reliability, the strategies suggested by Shenton [29] were adopted. First, for credibility, the present study used known methods of participant observation and document analysis to frame the narrative; the methods were familiar to the author. In addition, the study highlights related previous research, providing a reference for understanding and interpretation. Secondly, for transferability, extensive descriptions of the participants, data collection methods, amount of data plus duration of the workshops, and the period during which the study took place are provided. Thirdly, for confirmability, the study provides an audit trail (Table 1) and figures from the GDWs and the workshop materials (Figure 1). Finally, for dependability, a thorough outline of the research design, its execution, the data collection, and the data analysis is presented.

\section{Results}

\subsection{Theme 1: Misconceptions about gamification}

In the GDWs, there appeared to be a (mis)understanding that gamification was a fullyfledged game (OFN1-4). Questions arose at various moments about how the envisioned game would come to look or how the studio should incorporate the game into the COTP. The specialists' perception seemed to be that the studio would produce a learning game (OFN2, $3)$. There was also a perception among the specialists that GWEN from the gamification studio would take the course material and convert it into a browser game playable within the learning management system (OFN1). These misconceptions caused the GDW to backtrack, and the GD had to recite what GWEN intended to do with the course material (OFN1,3). This misunderstanding led to frustration during the GDWs. In some cases, tension occurred after repeated explanations of the concept (OFN2,4,5). The misunderstanding was audible in dialogues between the gamification studio and the specialists, and it was a pattern of communication that emerged in several GDWs (OFN1,3,4,5). The specialists repeatedly referred to the gamified course as "the game" (OFN2), "the learning game" (OFN3), or "the onboarding game" (OFN3). Moreover, expressions from the specialists linked gamification to imagery concerning the activity of playing games: "I have seen my son play. He can be at it for hours. I want our course to function like that" 
(OFN4); "I would like to see what the game will look like; when can you deliver the mockups?" (OFN5); "The employees need to understand why they should play the game" (OFN3); "It is an obstacle to get the employees actually to download the game; how do we do this? How do we sell the concept to them?" (OFN2). The cognitive dissonance often became problematic in the final stage of the GDW, which concerned the gamified course design. Here, the uncertainty around what the discussion was about (is it a game or is it something else?) peaked, which led to frustration. For some specialists, the frustration created a disinterest in the GDW (OFN2,4,6). Even after the final stage, comments on how the game would look when completed were made (OFN2,5,6). This theme indicates that it can be challenging to communicate the concept of gamification. This communication problem caused obvious friction in several of the GDWs (OFN1,4,5,6) and was triggered by misinterpretations or a lack of a unified understanding of the purpose of the GDWs.

\subsection{Theme 2: Perceptions of the usefulness of gamification for corporate training}

In the GDWs, there was a concern that the intended end-users of the COTPs would not see the benefit of a gamified course. This apprehension was perceived as a significant challenge for implementing gamification for several of the specialists. To counteract this perceived obstacle, the discussions about gamified training focused on providing direct value to avoid risking the end-users' distrust of it $(\mathrm{OFN} 3,6)$. The specialists described their end-users as demanding and stated that corporate content had to be useful and understandable, and not added as "fluff" or a "fun layer" (OFN3,6). The end-users needed to see the point of gamification to engage in it (OFN2,3): if the end-users did not perceive benefits early, they would not bother (GDD5). The endusers required a purpose in order to bother engaging in the gamification; they would not be motivated by playful exploration or light-hearted "trial and error" design (GDD3). It was also underlined, with great emphasis, that the implementation could not, under any circumstances, make the COTP "look like a kindergarten" (OFM6). The specialists clarified that their end-users were not students, they were tougher to please, and that the timeframe for training was narrow $(\mathrm{OFN} 3,6)$. The specialists stated that a university course and a training course are dissimilar: university students are more motivated than corporate end-users (OFN3,6). It was considered that, to succeed in applying gamification in COTPs, an effort had to be made to convince the end-users that gamified learning had an advantage over a traditional approach (OFN1,3,6; GDD1,6). Specialists said, "The first step [with their gamified course] is to show the benefits of gamified learning" (OFN1) and "We have to make them understand the value in taking part in the gamified onboarding: to be able to learn, understand, and perform faster" (OFN3). Similar expressions were experienced in the majority of the GDWs $(\mathrm{OFN} 1-4,6)$ and also occurred in both the design documents (GDD1,3,4) and the designers' notes (GDPN1,3). The specialists stated the need for "a carrot" (GDPN4) to entice employees to take interest in or to remain interested in the COTP $(G D D 3,4)$ and that the end-users needed to see the benefits of becoming involved in the game (GDPN3). The GDPNs stated that the end-users "need[ed] an obvious "Why' to accept" the gamified COTPs (GDPN3,6). Similar statements occurred in the GDDs and were noted in the OFNs (GDD1,3-5) (OFN1,3,5).

\subsection{Theme 3: Employees' negative attitude towards gamification}

In all the GDWs, the discussions often focused on, and returned to, a particular end-user demographic deemed significant for COTPs. These end-users formed the largest group by a wide margin. This group was also acknowledged as the most critical because they needed COTPs for the new types of skill required for their current profession. At the same time, they were also labeled particularly recalcitrant to COTPs and were therefore presumed to be negative towards a gamified approach. Nonetheless, the group was expected to benefit from a gamified content due to their previous low engagement in COTPs. This cluster gained attention in the majority of the GDDs (2-6) and was highlighted in the GDPNs $(1,3,4,6)$. They are also noted in all the OFNs. Although there were various descriptions and labels for the group in the GDWs, they were given the same characteristics by the specialists. The group was described to have been employed in the business for more than 20 years (OFN2-4,6). They had several years left before retirement, and therefore it was crucial for them, as well as the manufacturing industry as a whole, to commence and complete training (OFN1,3,5; GDPN2-4; GDD2-4). In GDD1-3 and 6, the group was given an age span of 45-60 years old, which gave them approximately 5-20 years until retirement. The group was described as consisting mostly of males (approximately $80-85 \%$ ), according to GDD3 and 5. The group was described as blue collar (employees who perform manual labor in a factory) in GDD3 and OFN3 and as operators in GDD2, 4, and 5 and OFN2, 4, and 5, which indicates that the group had a limited educational background.

The specialists who had experience working with digital transformation in the manufacturing 
industry identified the group as reluctant, in general, to accept digitalization in the workplace (GDD1,2). The specialists mentioned previous negative experience with this group concerning COTPs and therefore suspected that it would be difficult for gamification to be accepted (OFN1,2,5,6). The group was described as "somewhat antagonistic" (OFN2) to the fast digitalization of the workplace, in general, which was viewed as an indicator that the group would not accept gamified course content (GDD4; OFN4). It was expressed that the group had developed an unhealthy mentality, asking, "Why does everything need to be digitalized? Can't it be more oldfashioned?" and that this had grown into a direct aversion to and suspicion of all digital innovations in the company (OFN3; GDPN3). Some specialists seemed sincerely concerned about discussing these end-users and described it as complicated because digitalization is vital in transformations towards a smart factory (OFN6). The transformation had to be completed, otherwise the company would fall behind in the intensive international competition (OFN6). The group also appeared in the GDPNs, in which the group was described as challenging due to their "opposed thoughts of digitalization," "preferred analog ways of doing things," and "aversion to the fast technology shift" in the workplace and as "afraid of change" (GDPN1,2,5). The sub-groups "presumptions and misunderstanding of what gamification is" and "the toughest crowd of the groups" were also noted (GDPN2,3,6). At the same time, the specialists considered the group to be a valuable resource because of their long work experience, considerable knowledge of the companies, and the fact that many employees respected them because of their experience in the profession (which bestowed on them informal authority).

The GDW discussions emphasized the gamification studio's need to produce the gamification with this group in mind (OFN1,5,6). The specialists and GDs discussed and agreed to make the "look and feel" of the course's gamification more sophisticated (GDPN3), "less game-y and playful," (OFN3), and more comparable to "a to-do list with achievements" (OFN3).

\section{Discussion}

The key finding of the present study is the theme "Misconceptions about gamification," which considers the definitions of gamification and the confusion over what it is or is not. Referring to gamification as a game in the GDWs, talking about their children playing video games, and asking about how the intended game will materialize when delivered indicates a preconceived notion of what gamification involves.
When the GDs explained what their platform did, the specialists still did not visualize the upcoming course in that way. Working through the misunderstanding of gamification as a concept expended effort in all the GDWs. This communication problem caused friction, because it leaked into misinterpretations of the overall concept and goal. Something was lost in the translation between the designers and the specialists, causing confusion in the GDW about the meeting's outcome. Similar presumptions and outcomes can be found in the study by Hassan et al., which described internal conflicts in a multipart gamification project due to differences between participants' experiences and understanding of gamification [15]. The circumstance provokes one to consider whether the specialists had been affected by the hype surrounding gamification (e.g., [9][22]) and whether they, at the last minute, were uncertain that they were making the right choice to implement it in the COTPs. A valid point could be made here that the gamification studio may lack the proper communication skills for clarifying the difference between a gamified course and a digital game before the GDWs take place.

The definitions of gamification in a businessto-business context should benefit from being more distinct and more precise than "Gamification is using elements from the world of games in a non-gaming environment" [23]. For professionals working with gamification and their clients, perhaps this definition, adapted from the academic world, is too abstract and leaves too much room for interpretation for direct business-to-business exchanges. The confusion could be detrimental to the business field of gamification. Clients are unlikely to want to purchase "a pig in a poke". Defining gamification may be more successful from the vantage point of what it is not. Therefore, in a businessto-business situation, the definition could start with "Gamification is not about games or gaming". This reasoning contributes to the existing literature on definitions of gamification [30]-[32]. Landers et al. argue that gamification is not in itself a product that is differentiated from a game; instead, it has a stronger footing in behavioral principals and human-computer interaction heuristics than games have [32]. The "Misconceptions about gamification" theme strengthens previous gamification design research that has argued that the analysis phase (prior to the design phase) could be of importance for making meaningful and welldesigned gamification [9][15][16]. The theme also reflects the research and literature on how to gamify [7] [8], especially when working with design gamification for a client. A final deduction from this key theme generates the following research proposition (RP1): a more substantial definition of gamification is required to 
modulate expectations, reduce the hype, and prevent frustrations in business-to-business transactions than in the research field.

For the gamification professionals and specialists, the theme "Perceptions of the usefulness of gamification for corporate training" related to the usefulness (performance versus effort) of implementing gamification in COTPs. In the GDWs, it was stated several times that employees needed to perceive fast benefits from gamification and that the end-user required instant notions that their learning performance would improve because of the gamified implementation; otherwise, implementation was not worthwhile. The specialists argued that the target groups for COTPs in the manufacturing sectors were not comfortable exploring course material: they needed to see rapid results. One interpretation of the specialists' claims could be that the end-users would question the motive of the training and the reason for the implemented game-mechanics if they could not grasp the mechanics' usability. This indicates that increased learning performance is highly valued in COTPs. This finding concurs with previous research regarding the difference between education and training [5][10]. Likewise, the difficulty with the end-users' lack of understanding of the purpose of the technology has arisen in other studies [33][34]. The specialists depicted their end-users through comparisons with university students who, according to the specialists, appreciate juvenile exploratory moments in a course. Correspondingly, the specialists seemed to assume that gamifying a learning setting by default alters the course design by adding childish and playful elements and motivating ridiculous and hedonic exploration, which is undesirable. The assumption that gamification's sole aim is to add a fun layer to serious situations has been identified in previous studies regarding software development and gamification [35]. This indicates that the gamification of COTPs must consider that the effort that the intended end-user can expend is much more limited than that of a university student, at least in the eyes of a business specialist. It should not be overlooked that the specialists' sentiments may be based on the fact that retraining is costly for a company, not that the endusers do not appreciate it. Specialists may desire a briefer course timeframe, therefore, limit the incentives redundant course exploration. The gamification could be viewed as a tool to cut costs rather than to make COTPs more enjoyable for the end-user, increasing the quantity of output for the same amount of effort. This second theme indicates that gamification in COTPs is not automatically accepted by the end-users or the clients. Rather, a gamified implementation in the manufacturing industry will endure exceptional scrutiny regarding the expected invested effort versus the expected gain in performance. This reasoning is strengthened by Olivera et al .[13], who have observed similar findings regarding the performance and effort required for the end-users to care about gamification. Additionally research on technology acceptance posits that performance gain versus the effort invested affects the acceptance and usage of technology [14][34]. A final deduction from this theme generates the following research proposition (RP2): gamification implementations in corporate training must clarify how the invested effort (for the stakeholders/end-users) is outweighed by the performance gain (for the stakeholders/end-users).

The theme 'Employees' attitude towards gamification" considered a particular demographic group's attitude toward gamified online training. The attitude originated from an unwillingness to change, adapt, and take part in the digital transformation. The group was highlighted as the most important in the GDW due to its large size. Despite the specialists' description of the group as gamification-averse, the specialists still considered gamification to be a valuable method to use in the learning context, probably due to the prospect of increasing course completion rates. It was emphasized that the gamified training should be designed to appeal to this demographic group by not appearing to be disruptive, but rather by evoking a sophisticated atmosphere; otherwise, the end-users would not accept it. This discussion was present, in some form, in all the GDWs. The assumption could be related to the belief that young people play more video games than their seniors do and therefore are more open to gamification, which advocates the presumption that senior end-users have difficulties with accepting gamification if it looks too "game-y." One can interpret concerns about the "game-y look" as a predisposition toward young adults' being perceived as more attracted to games and gamification. Similar assumptions have been mentioned in previous research [5][11]. However, this belief may not be accurate. The specialists' reasoning originated from the experience that, previously, this group had been uninterested in digitalization projects and the assumption that therefore they would be uninterested in gamification. The discussion about the group's attitude to gamified training need not concern gamification but, rather, the digital divide between younger and older generations. This is strengthened by findings in previous research on technology acceptance and age [14]. Nevertheless, the group's perceived uninterest could also be due to the lack of enough beneficial conditions in previous COTPs to facilitate the corporate training. In addition, the sentiment that the gamified course should look 
sophisticated and mature could depend on a local frame of reference in the companies rather than on the endusers. Advocating for gamification seriousness may not exclusively concern gamification: it may also appertain to corporate history and legacy. The retraining programs in all the participating companies played a vital part in their future, and it could be that the specialists in the GDWs did not want to risk blemishing their company's image and impeccable reputation, hard-won over the previous century. The specialists could also have been influenced by social norms existing in the manufacturing industry, which they considered would function as judgments for having used an overly disruptive and norm-breaking technology. This also relates to the discussion about ensuring that the implementation did not make the training resemble a kindergarten. Social norms are a recognized variable in research on the acceptance of technology [14]. A final deduction from this third theme generates the following research proposition (RP3): gamification implementation in the manufacturing industry must consider the senior user and/or the social norms that exist in the industry.

\section{Conclusion}

This study has introduced three reoccurring discussion themes between GDs and specialists when they prepare to implement gamification in digital corporate (re-)training courses. Considering these themes, when implementing gamification in training for manufacturing companies, potential (mis)conceptions and (mis)communication that arises in the translation between business fields can be avoided. The study's findings could benefit both researchers and professionals to circumvent potential barriers starting gamification projects for adult learners general, not only the manufacturing industry. However, each finding of this study requires a more pervasive investigation; therefore, the following section presents three research propositions for future studies.

\section{Future research}

Future research may find value in exploring whether the obstacles expressed in this study exist or if they are merely subjective and preconceived notions conveyed by the specialists in the GDWs.

RP1 should be explored in a separate study investigating how gamification professionals clarify gamification. It would be noteworthy to investigate how different business fields discuss and describe the gamification term. It could be beneficial to consider the subject of serious games' effects on the perception of gamification. Such an investigation would reduce the vagueness surrounding gamification and promote progress in the gamification business, as well as in the research field, providing knowledge useful to researchers, gamification salespersons, gamification clients, and GDs alike.

RP2 would benefit from a more in-depth investigation of end-users' attitudes concerning gamification regarding effort and performance. In this investigation, it would be beneficial to use the UTAUT model. The weakness in RP2 is that it derives from the stakeholders' decision to implement gamification. Research on gamification design, as well as humancomputer interaction, has highlighted that it is essential to have the views and needs of the user in mind when designing devices, interfaces, and online courses. Therefore, an investigation that includes the users would contribute more to discovering what kind of gamified implementation would benefit the end-users rather than be profitable for the corporations. The proposed findings could benefit GDs working in the manufacturing industry and generate exciting research topics for future research.

RP3 indicates that further studies regarding senior demographic groups' responses to gamified courses would be of interest. Future studies could verify or disprove the claim that there are obstacles with gamified COTPs and seniors. It should also be investigated if social norms in the manufacturing industry obstruct the use of gamified COTPs. This proposition suffers the same weakness as the second; that is, it derives from the stakeholders. The author therefore stresses the need to engage the abovementioned demographic groups in further studies.

\section{Acknowledgements}

The study was partly supported by Vinnova (201802953). The author of this study works at the gamification studio. The research is part of a development work at the studio with the purpose of providing insights into how the team co-operates with their newly developed gamification platform GWEN. Parts of the data in this study have previously been presented at GamiFIN 2020. The study is part of the GamiFIN 2020 Gamification fast track to HICCS 2021. It has been reworked and expanded with feedback gained from reviews prior to and discussions at the conference, as agreed with the GamiFIN chair.

\section{References}

[1] James Manyika et al., "Jobs Lost, Jobs Gained: Workforce Transitions in a Time of Automation," McKinsey Glob. Inst., no. December, 2017, p. 160, Accessed: Aug. 05, 2019.

[2] J. Jaana Remes, "Solving the Productivity Puzzle: The 
Role of Demand and the Promise of Digitization," Int. Product. Monit., vol. 34, 2018, pp. 28-51,

[3] A. T. Leopold, V. S. Ratcheva, and S. Zahidi, The Future of Jobs Report 2018 Insight Report Centre for the New Economy and Society. 2018.

[4] P. Denny, "The effect of virtual achievements on student engagement," in Proceedings of the SIGCHI conference on human factors in computing systems, 2013, pp. 763772.

[5] M. B. Armstrong, R. N. Landers, and A. B. Collmus, "Gamifying recruitment, selection, training, and performance management: Game-thinking in human resource management," in Emerging research and trends in gamification, IGI Global, 2016, pp. 140-165.

[6] M. B. Armstrong and R. N. Landers, "Gamification of employee training and development," Int. J. Train. Dev., vol. 22, no. 2, Jun. 2018, pp. 162-169.

[7] B. Morschheuser, K. Werder, J. Hamari, and J. Abe, "How to gamify? A method for designing gamification," Proc. 50th Annu. Hawaii Int. Conf. Syst. Sci. (HICSS), Hawaii, USA, January 4-7, 2017, no. January, 2017, pp. 1298-1307.

[8] A. Shahri, M. Hosseini, K. Phalp, J. Taylor, and R. Ali, "How to engineer gamification: The consensus, the best practice and the grey areas," 2019.

[9] J. Koivisto and J. Hamari, "The rise of motivational information systems: A review of gamification research," Int. J. Inf. Manage., vol. 45, 2019, pp. 191-210.

[10] L. A. Burke and H. M. Hutchins, "Training transfer: An integrative literature review," Hum. Resour. Dev. Rev., vol. 6, no. 3, 2007, pp. 263-296.

[11] J. Hamari and J. Koivisto, "Why do people use gamification services?," Int. J. Inf. Manage., vol. 35, no. 4, 2015, pp. 419-431.

[12] M. B. Armstrong and R. N. Landers, "An Evaluation of Gamified Training: Using Narrative to Improve Reactions and Learning," Simul. Gaming, vol. 48, no. 4, 2017, pp. 513-538.

[13] L. C. de Oliveira, L. H. C. Pinochet, R. L. P. Bueno, and M. A. de Oliveira, "Effect of gaming on behavioral intention to use online training," Rev. Adm. UFSM, vol. 12, no. 3, 2019, pp. 472-491.

[14] V. Venkatesh, M. G. Morris, G. B. Davis, and F. D. Davis, "User acceptance of information technology: Toward a unified view," MIS Q. Manag. Inf. Syst., vol. 27, no. 3, 2003, pp. 425-478.

[15] L. Hassan, B. Morschheuser, N. Alexan, and J. Hamari, "First-hand experience of why gamification projects fail and what could be done about it," in CEUR Workshop Proceedings, 2018, vol. 2186, pp. 141-150, Accessed: Jul. 02, 2019.

[16] S. Deterding, "The lens of intrinsic skill atoms: A method for gameful design," Human-Computer Interaction, vol. 30, no. 3-4. Taylor and Francis Inc., pp. 294-335, May $01,2015$.

[17] M. Raftopoulos, "Has Gamification Failed, or Failed to Evolve? Lessons from the Frontline in Information Systems Applications," 2020.

[18] B. Burke, "Gartner Says by 2014, 80 Percent of Current Gamified Applications Will Fail to Meet Business Objectives Primarily Due to Poor Design" Gartner.com
(November 27, 2012)," Gartner.com

[19] L. Goasduff and C. Pettey, "Gartner says by 2015, more than 50 percent of organizations that manage innovation processes will gamify those processes," Recuper. http//www. gartner. com/it/page. jsp, 2011.

[20] M. Dymek and P. Zackariasson, The business of gamification: a critical analysis. Taylor \& Francis, 2016.

[21] A. Lieberoth, N. Holm Jensen, and T. Bredahl, "Selective psychological effects of nudging, gamification and rational information in converting commuters from cars to buses: A controlled field experiment," Transp. Res. Part F Traffic Psychol. Behav., vol. 55, 2018, pp. 246261.

[22] L. E. Nacke and S. Deterding, "The maturing of gamification research," Comput. Human Behav., vol. 71, Jun. 2017, pp. 450-454.

[23] https://insertcoin.se Accessed 2020-06-15

[24] G. A. Bowen, "Document analysis as a qualitative research method," Qual. Res. J., vol. 9, 2009, pp. 27-40.

[25] J. Preece, Y. Rogers, and H. Sharp, Interaktionsdesign : bortom människa-dator-interaktion, 1:1. Lund: Studentlitteratur, 2016.

[26] J. Lazar, J. H. Feng, and H. Hochheiser, Research methods in human-computer interaction, 2nd ed. Morgan Kaufmann Publishers, 2017.

[27] T. Ishida, Field Informatics. Berlin, Heidelberg: Springer Berlin Heidelberg, 2012.

[28] M. J. Belotto, "The Qualitative Report Data Analysis Methods for Qualitative Research: Managing the Challenges of Coding, Interrater Reliability, and Thematic Analysis," 2018.

[29] A. K. Shenton, "Strategies for ensuring trustworthiness in qualitative research projects," Educ. Inf., vol. 22, no. 2, 2004, pp. 63-75.

[30] S. Deterding, D. Dixon, R. Khaled, and L. Nacke, From game design elements to gamefulness: Defining "gamification." 2011.

[31] K. Huotari and J. Hamari, "Defining gamification: a service marketing perspective," in Proceeding of the 16th international academic MindTrek conference, 2012, pp. $17-22$.

[32] R. N. Landers, E. M. Auer, A. B. Collmus, and M. B. Armstrong, "Gamification Science, Its History and Future: Definitions and a Research Agenda," Simul. Gaming, vol. 49, no. 3, Jun. 2018, pp. 315-337.

[33] N. Hauk, J. Hüffmeier, and S. Krumm, "Ready to be a Silver Surfer? A Meta-analysis on the Relationship Between Chronological Age and Technology Acceptance," Comput. Human Behav., vol. 84, 2018, pp. 304-319.

[34] A. Pucihar, M. Kljajić Borštnar, C. Kittl, P. Ravesteijn, R. Clarke, and R. Bons, "30th Bled eConference: Digital transformation-from connecting things to transforming our lives:(J Bled, Slovenia)(conference proceedings)," 2017, p. 764.

[35] A. Palmquist, "A product to gamify other products; implementing gamification in existing software," in 2019 11th International Conference on Virtual Worlds and Games for Serious Applications (VS-Games), Sep. 2019, pp. 1-8. 